
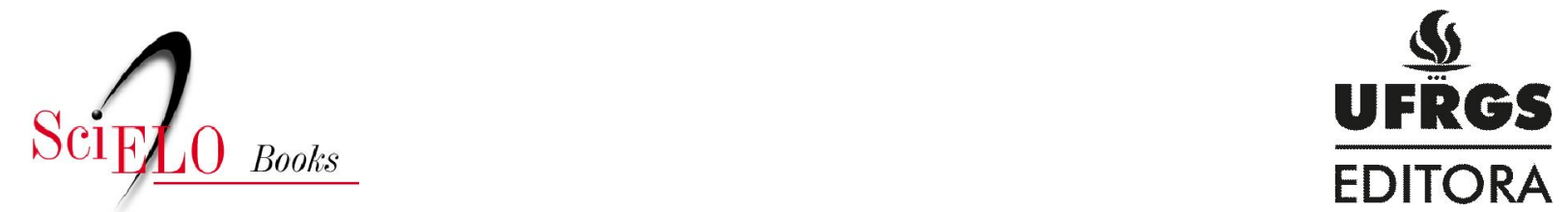

\title{
Por uma sociologia dos meios e das redes partidárias
}

\author{
Frédéric Sawicki
}

\section{SciELO Books / SciELO Livros / SciELO Libros}

SAWICKI, F. Por uma sociologia dos meios e das redes partidárias. In: MARENCO, A., org. Os eleitos: representação e carreiras políticas em democracias [online]. Porto Alegre: Editora da UFRGS, 2013, pp. 11-29. ISBN 978-85-386-0384-9. Available from doi: 10.7476/9788538603849. Also available in ePUB from: http://books.scielo.org/id/bfwrk/epub/marenco-9788538603849.epub.

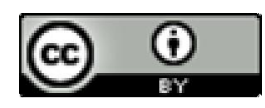

All the contents of this work, except where otherwise noted, is licensed under a Creative Commons Attribution 4.0 International license.

Todo o conteúdo deste trabalho, exceto quando houver ressalva, é publicado sob a licença Creative Commons Atribição $\underline{4.0}$.

Todo el contenido de esta obra, excepto donde se indique lo contrario, está bajo licencia de la licencia $\underline{\text { Creative Commons }}$ Reconocimento 4.0. 


\section{Por uma sociologia dos meios e das redes partidárias ${ }^{1}$}

Frédéric Sawicki*

Esquematizando ao extremo, podem-se classificar as análises sociológicas dos partidos políticos em duas grandes categorias, de acordo com o que elas enfatizam sobre a heteronímia ou a autonomia destes em relação às forças sociais. Esta distinção encontra em parte sua origem científica na oposição entre a tradição weberiana e a tradição marxista de análise da política. Sabe-se, com efeito, que para Max Weber, os partidos são principalmente agrupamentos "que têm por finalidade conceder a seus chefes o poder", ${ }^{2}$ enquanto que para autores marxistas, em conformidade com a hipótese da determinação da superestrutura política pela infraestrutura socioeconômica, a taxionomia dos partidos corresponde antes de tudo àquela dos grupos ou dos estratos de classes sociais. Antonio Gramsci é sem dúvida o pensador marxista que tratou desta questão de maneira mais sistemática. Para ele, não é de se duvidar que todo partido seja "a expressão de um grupo social e de um único grupo social". Se alguns partidos rivais se apresentam como representantes de uma mesma classe social, ou outros, como a expressão de várias classes sociais, isso se explica, segundo ele, por duas razões principais: por um lado, a existência de interesses divergentes que dividem a classe dominante em muitos estratos (ideia já presente no Marx do 18 Brumário); por outro lado, desacordos estratégicos a respeito dos meios mais aptos para favorecer os interesses de classe. Dentre esses desacordos, o principal aborda

\footnotetext{
* Professor da Universidade de Paris I

${ }^{1}$ Tradução do francês para o português por Weslin de Jesus Santos/UFS. Revisão da tradução por Dominique Marie Philippe Geneviève Boxus/UFF)

${ }^{2}$ WEBER, M. Économie et société. Plon, p. 292 (1ère éd. 1922), 1971.
} 
a questão das alianças a serem concluídas com outros grupos sociais para conquistar ou conservar o poder. Mas, quando o essencial está em jogo, isto é, a sobrevivência do sistema de exploração econômica, essas divergências desaparecem e a unidade dos partidos que representam uma mesma classe social se reconstitui para formar "bloco". ${ }^{3}$

Certamente, esta maneira de resumir as grandes correntes da sociologia dos partidos políticos é por sua vez demasiadamente redutora e largamente obsoleta. Ao lado das análises que chamaremos de sociais, as pesquisas inspiradas no marxismo foram refinadas, até mesmo ultrapassadas: por um lado, por trabalhos que, apoiando-se na história cultural e na política comparada, puseram em evidência a diversidade e a complexidade das clivagens sociopolíticas e de sua tradução partidária; ${ }^{4}$ por outro lado, pelos inumeráveis estudos quantitativos fundados sobre o conjunto de questionários aplicados com dirigentes, militantes, adeptos ou eleitores dos partidos, que lançam luzes sobre seu caráter socialmente composto e a complexidade das variáveis que explicam a adesão ou a identificação com um dado partido. Estas pesquisas não chegaram, entretanto, a superar as aporias do marxismo aplicado ao estudo dos partidos, ou seja, sua redução a expressões de clivagens sociais e o pouco de atenção dispensada ao trabalho prático e simbólico efetuado no meio mesmo dos partidos, trabalho que chega a manter, e até mesmo, a criar estas clivagens. ${ }^{5}$ Em alguns casos, os partidos contribuem, com efeito,

3 "La vérité théorique selon laquelle chaque classe a un seul parti, est démontrée, dans les tournants décisifs, par le fait que les regroupements divers qui tous se présentent comme parti "indépendant" se réunissent et forment un bloc unique. La multiplicité qui existait auparavant était uniquement de caractère 'réformiste', c'est-à-dire qu'elle concernait des questions partielles; en un certain sens, c'était une division du travail politique (utile, dans ses limites); mais chacune des parties présupposait l'autre, au point que dans les moments décisifs, c'est-à-dire précisément quand les questions principales ont été mises en jeu, l'unité s'est formée, le bloc s'est réalisé." A. Gramsci, Note sul Machiavelli, sulla politica e sullo stato moderno, 1933, p. 28, traduit dans Textes (1917-1934), Paris, Éditions sociales, 1983, p. 176-180. [consultar a tradução espanhola disponível]

${ }^{4}$ Cf. principalmente LIPSET, S.; ROKKAN, S. (Eds.). Party Systems and Voter Alignment. New York, The Free Press, p. 1-64, 1967 et SEILER, D-L. Partis et familles politiques. Paris, Presses universitaires de France, 1980.

5 Podemos encontrar uma discussão crítica da abordagem sociocultural dos partidos politicos em Giovanni Sartori, "The Sociology of Parties: a critical review”. In: MAIR, P. (Ed.). The West European Party System. Oxford University Press, p. 150-182 (1ère éd. 1968), 1990. 
não apenas a dar forma, mas a legitimar e a deslocar as linhas de clivagem que atravessam uma dada sociedade. S. Rokkan, reconheceu que a nova clivagem instituída pelo comunismo foi fruto da revolução soviética e do trabalho entreposto pela Internacional comunista para difundir pelo mundo, com um sucesso sem igual, o modelo do partido bolchevique. Em resumo, as análises sociais - se elas tiverem o imenso mérito de não apreender os partidos políticos independentemente da sociedade em que desempenham suas atividades - levaram frequentemente a tratar os partidos políticos como caixas pretas, até mesmo como entidades homogêneas no tempo e no espaço, mais do que como empresas coletivas caladas por interesses diversos, atravessadas por mudanças incessantes e suscetíveis de usos muito diferenciados.

Na linha da obra de Weber, mas também da obra de Ostrogorski ${ }^{6}$, de Michels ${ }^{7}$ e depois de Schumpeter ${ }^{8}$, as abordagens organizacionais constituem a segunda grande corrente da sociologia dos partidos. Elas ignoram, em sua maioria, as características sociais dos membros dos partidos e focalizam sua atenção nas lutas de poder que se desenrolam em seu próprio meio, isto é, para o essencial sobre os mecanismos de seleção dos dirigentes, sobre as lutas internas e sobre os recursos colocados em prática na conquista das posições de poder. Largamente dominante em ciência política, concomitantemente com a análise dos sistemas de partidos, esta corrente de pesquisa, simbolizada pelo livro pioneiro de Maurice Duverger, ${ }^{9}$ produziu muitos trabalhos marcantes. ${ }^{10}$ Os partidos não se aparentam mais aqui às caixas pretas evocadas mais acima, mas são dissecados, e, sobretudo, classificados em função das formas de organização

6 OSTROGORSKI, M. La démocratie et les partis politiques. Paris, Fayard, 1993 (1ère éd. 1903).

7 MICHELS, R. Les partis politiques. Essai sur les tendances oligarchiques dans les démocraties, Flammarion, (1ère éd. 1911), 1971.

8 SCHUMPETER, J. Capitalisme, socialisme et démocratie. Paris, Payot, (1ère éd. 1942), 1990.

9 DUVERGER, M. Les partis politiques. Paris, Armand Colin, 1951.

${ }^{10}$ Dentre os textos teóricos mais significativos, podemos citar: Samuel Eldersveld, Political Parties: A Behavioral Analysis, Chicago, Rand McNally, 1964; Otto Kirchheimer, "The Transformation of the Western European Party Systems". In: LaPALOMBARA, J.; WEINER, M. (Eds.), Political Parties and Political Development. Princeton, Princeton University Press, p. 177-200, 1966; SCHLESINGER, J. A. "Political Party Organization". In: MARCH, J. G. (Ed.). Handbook of Organizations. Chicago, Rand McNally, p. 764-801, 1965. 
e de leadership que os especificam. Quanto ao "entorno" que determina suas estratégias, ele é, na maior parte do tempo, reduzido às variáveis políticas, principalmente o próprio sistema de partidos, o regime político e o modo de votar. Desde a célebre distinção construída por M. Duverger entre partidos de quadros e partidos de massas, os pesquisadores em ciência política consagraram muita energia ao pôr em ordem novas categorias: as noções de catch-all-party (Otto Kirchheimer), stratarchic party (Samuel Eldersveld), electoral-professional party (Angelo Panebianco ${ }^{11}$ ), e mais recentemente a de cartel-party (Richard S. Katz e Peter Mair ${ }^{12}$ ), vieram enriquecer progressivamente o arsenal dos estudos políticos ao sabor de mutações sociopolíticas, com destinos diversos.

\section{A construção social das organizações políticas}

Desde a aparição do livro de Duverger, um politólogo francês, Georges Lavau, criticara "a explicação dos partidos pelos partidos e pelo regime eleitoral" proposta por Duverger, assim como sua escolha de considerar "o partido político como uma comunidade de estrutura peculiar" caracterizando-se "antes de tudo por sua autonomia". Georges Lavau advertia sobre os limites das tipologias exclusivamente organizacionais. "Um partido fascista pode calcar sua organização sobre a do partido comunista, inserir-se em um mesmo sistema partidário, escrevia ele, a semelhança será apenas morfológica, isto é, formal, deixando escapar o essencial que só pode ser explicado precisamente com o auxílio da doutrina e da composição social. Em um grau menor, poderíamos ainda sublinhar diferenças tão fundamentais entre dois partidos comunistas, um inserido em uma sociedade de tipo agrícola e outro em uma sociedade de tipo industrial." E concluía ele: "Não é apenas o estudo da doutrina e da composição social dos partidos que falta, com efeito, à obra de Duverger, mas sobretudo o estudo dos tipos de sociedade e civilização em que se movem os partidos, o das condições econômicas e das circunstâncias históricas nas quais eles evoluem."13 Dito de outra forma, "os partidos políticos não constituem, abstratamente, co-

${ }^{11}$ PANEBIANCO, A. Political Parties. Organization and Power. Cambridge University Press, (1ère éd. 1982), 1988.

${ }^{12}$ KATZ, R. S.; MAIR, P. "Changing Models of Party Organization and Party Democracy: the emergence of the cartel party". Party Politics, 1 (1), p. 5-28, 1995.

${ }^{13}$ LAVAU, G. Partis politiques et réalités sociales. Paris, Armand Colin, p. 7, sublinhado por nós, 1953. 
munidades definidas a priori pela sua estrutura: em primeiro lugar, são grupos oriundos de uma dada sociedade nacional e, no interior desta, de grupos particulares formados ao redor de interesses, de afinidades ou de formas de sociabilidade mais ou menos diferenciadas e caracterizadas." 14

A crítica de G. Lavau foi pouco entendida e depois esquecida. Em parte, por causa da fraca cultura sociológica de numerosos especialistas em ciência política da época, e também, sem dúvida, por causa de seu lado excessivo. De fato, este último, tal como Gramsci minimiza os efeitos da profissionalização política engendrada pela generalização do sufrágio universal. A aparição de empresários da política especializados na "caça ao voto" (políticos profissionais, permanentes nos partidos, jornalistas políticos...) levou estes últimos a desenvolver suas próprias estratégias de preservação de suas posições. Essas estratégias podem estar em contradição com os interesses da classe social de que eles são oriundos, até mesmo com os interesses de alguns dos grupos que eles pretendem representar em razão da diversidade social de seu eleitorado, mas, sobretudo, das estratégias de alianças que eles são obrigados a firmar para ter acesso ou se manter no poder. ${ }^{15}$ Esta automatização parcial do campo político justifica estudar de maneira autônoma a organização dos partidos e as estratégias que decorrem de sua participação no campo político, assim como a elaboração de tipos ideais destinados a sua comparação. No entanto, a tendência em fazer da classificação dos partidos a finalidade principal da pesquisa e a ignorar as propriedades sociais de seus membros tem incontestavelmente levado a simplificar a análise. É preciso constatar que, por exemplo, os estudos organizacionais não foram muito precisos em explicar a emergência ou o desaparecimento de certos partidos e, geralmente, de dar conta das mudanças incessantes que os atravessam. ${ }^{16} \mathrm{~A}$ teoria do partido-cartel, particularmente em voga na

\footnotetext{
${ }^{14}$ Ibid., p. 9.

${ }^{15}$ É o êxito relativo deste processo que registra a definição clássica do partido de J. La Palombara e M. Weiner, para quem um partido é uma organização durável, nacionalmente estruturada e hierarquizada, cujos dirigentes têm a vontade deliberada de conquistar o poder procurando adquirir um apoio popular, pelas eleições ou por outro meio. LaPALOMBARA, J.; WEINER, M. (Eds.). Political Parties and Political Development. Op. cit., p. 5. Sobre a gênese dos partidos nas principais democracias ocidentais, cf. POMBENI, P. Introduction à l'histoire des partis politiques. Paris, Presses universitaires de France, 1992 (1ère éd. 1985).

16 Esta crítica foi desenvolvida por Jacques Lagroye, "Change and Permanence in Political Parties”. Political Studies, 37 (3), p. 362-375, 1989.
} 
Europa, mesmo controversa, ilustra perfeitamente esta dificuldade em pensar os partidos em articulação com seu entorno social: ela defende a hipótese de que os partidos são separados da sociedade e funcionam doravante como caixas-pretas, sem explicar por que o surgimento de cartéis não atinge o mesmo grau de um país, até mesmo de um partido a outro. ${ }^{17}$

Alguns trabalhos recentes tentam felizmente superar a oposição intelectual relativamente esterilizante que foi forjada progressivamente entre análise social e análise organizacional, lançando as bases de uma problemática em termos de construção social das organizações partidárias. A teoria proposta por Michel Offerlé se revela, sob este ponto de vista, particularmente interessante, ao sublinhar os impasses intelectuais aos quais conduziu a classificação pela classificação dos partidos e o tratamento destes como entidades fixas. ${ }^{18}$ Michel Offerlé se apoia principalmente em Weber, Schumpeter e Pierre Bourdieu. ${ }^{19}$ Ele toma emprestado dos dois primeiros os conceitos de "empresa", de "empreendedores políticos" e de "mercado", e, de Pierre Bourdieu, os conceitos de "campo" e de "disposições sociais". Ele se esforça assim em relacionar os diferentes tipos de "empresas políticas" 20 com as disposições e os recursos sociais de seus dirigentes, evitando por meio disso apreender os "empresários políticos" como simples estrategistas ligeiramente determinados por suas disposições sociais. Nesse modelo, a forma tomada pela relação partidária, aberta ou fechada, burocratizada ou ligeiramente disciplinada, não

${ }^{17}$ Só podemos acrescentar aqui a crítica formulada por Ruud Koole: "Instead of using an evolutionary language, Katz and Mair could help us to understand their "cartel party" better if they would concentrate on developing propositions about the forces that tend to produce parties of the alleged cartel type. Why do these parties develop in certain countries and not in others? Or: why can some parties be called cartel parties and others in the same country cannot be characterized as such?. KOOLE, R. "Cadre, Catch-All or Cartel? A Comment on the Notion of the Cartel Party", Party Politics, 2 (2), p. 520, 1996.

${ }^{18}$ OFFERLÉ, M. Les partis politiques. Paris, Presses universitaires de France, 1987.

${ }^{19}$ Inclusive dois textos importantes de BOURDIEU, P. "La représentation politique. Éléments pour une théorie du champ politique". Actes de la recherche en sciences sociales, 36-37, p. 3-24, 1981 et "La délégation ou le fétichisme politique", Actes de la recherche en sciences sociales, 52/53, p. 49-55, 1984.

${ }^{20}$ Para Michel Offerlé um partido é uma empresa política, quer dizer, "un type particulier de relation dans laquelle un ou des agents investissent des capitaux pour recueillir des profits politiques en produisant des biens politiques", in Les partis politiques, op. cit., p. 22. 
aparece dada de uma vez por todas: estreitamente dependente dos recursos políticos e sociais dos dirigentes e de seus auxiliares, ela é também um dos motivos das confrontações com as quais se envolvem os membros do partido. Um dos principais interesses desta perspectiva reside desde então na sua vontade de conciliar o estudo relacional das disposições dos atores políticos e o de suas estratégias ou tomadas de decisão.

Esta pista promissora foi explorada de maneira particularmente exemplar por Bernard Pudal na sua análise da institucionalização do Partido Comunista Francês (PCF), ao longo dos anos $30 .{ }^{21}$ Mais do que imputar à ideologia comunista e ao controle pelo Komintem uma força intríseca, este último põe em evidência, recorrendo à biografia individual e coletiva dos chefes do partido, o que predispunha socialmente os primeiros dirigentes comunistas a se identificar assim com a instituição e confiar-se a ela, depois a fazer desta fidelidade uma norma absoluta dos códigos de militância. Ao desconstruir "o ator coletivo a fim de reconstituir os processos históricos e sociais pelos quais os atores individuais, na sua diversidade, agregam-se, excluem-se, institucionalizam-se", ${ }^{22}$ Bernard Pudal rompe com todo determinismo. Seu procedimento de compreensão fornece, além disso, uma tabela de leitura particularmente pertinente para compreender a gênese do sindicalismo do partido comunista francês (cujo culto à personalidade de Thorez e a de Stálin é uma das expressões), a ligação ao marxismo-leninismo das elites dirigentes, o estrito enquadramento dos eleitos no seio do partido e mais geralmente, os fundamentos dos conflitos internos.

Este trabalho leva a flexibilizar o quadro teórico definido por Michel Offerlé. Com efeito, ele pleiteia claramente em favor de uma perspectiva que recoloca o estudo dos partidos políticos em seu contexto sócio-histórico. A gênese dos partidos políticos na França aparece inseparável das transformações da classe operária francesa do pós-guerra, ${ }^{23}$ dos bloqueios do sistema educacional que restringe a promoção escolar das crianças das classes populares, ou ainda, do desenvolvimento da pequena e média fun-

\footnotetext{
${ }^{21}$ PUDAL, B. Prendre parti. Pour une sociologie historique du PCF. Paris, Presses de la FNSP, 1988.

22 Ibid., p. 14.

${ }^{23}$ Sobre estas transformações a melhor síntese é a de Gérard Noiriel, Les ouvriers dans la société française. XIXe-XXe siècle, Paris, Seuil, 1986.
} 
ção pública cuja parte crescentemente importante investiu no partido socialista e na CGT, fenômenos que produziram "um conjunto composto de situações identitárias críticas que os partidários da adesão à Internacional Comunista vão explorar". ${ }^{24}$ Em resumo, mesmo sendo centrado na organização, o estudo de Bernard Pudal demonstra que as ações dos dirigentes comunistas e as crenças que os guiam estão longe de obedecer apenas a finalidades estratégicas impostas pelas lógicas de concorrências próprias do partido e do sistema político. Elas se inscrevem em uma instituição e em uma sociedade em que se trata de refletir permanentemente em suas interdependências. ${ }^{25}$

Em virtude do caso paradigmático do partido comunista francês, os estudos específicos que lhe foram consagrados, nestes últimos anos, por especialistas de ciência política, ${ }^{26}$ historiadores ${ }^{27}$ ou sociólogos,${ }^{28}$ confirmam a pertinência desta perspectiva e vão adiante mostrando que os dirigentes nacionais e internacionais estão longe de serem os únicos a participar do trabalho de formatação do partido como grupo e como representação. Tentando compreender os mecanismos através dos quais este partido chegou historicamente a representar diversos grupos sociais ou corporações profissionais, estas pesquisas não apenas puseram em relevo a diversidade de usos da organização e da identidade comunistas, mas também a determinação do trabalho de mobilização em nível de partido por formas específicas de sociabilidade e de identidade local e/ ou sindical ou profissional. Se, segundo Bernard Pudal, o centralismo democrático e sindicalismo se explicam pela relação particular que entretêm os cargos dirigentes com a identidade operária, estas monografias

\footnotetext{
${ }^{24}$ PUDAL, B. Prendre parti..., op. cit., p. 35.

${ }^{25}$ Sob este ponto de vista, a abordagem de Bernard Pudal é mais satisfatória que a de A. Panebianco. (Political Parties..., op. cit.) que tende a considerar a dependência institucional de maneira cristalizada e determinista, ao ponto falar de um modelo genético.

${ }^{26}$ HASTINGS, M. Halluin la rouge: 1919-1939. Aspects d'un communisme identitaire: singularités écologiques et stratégies d'implantation, Villeneuve d'Ascq, Presses universitaires de Lille, 1991.

27 NOIRIEL, G. Longwy, immigrés et prolétaires (1880-1980). Paris, Presses universitaires de France, 1984; Annie Fourcaut, Bobigny, banlieue rouge, Paris, Éditions ouvrières/Presses de la FNSP, 1986.

${ }^{28}$ BONNET, S. Sociologie politique et religieuse de la Lorraine, Paris. Armand Colin, 1972; Jean-Paul Molinari, Les ouvriers communistes, Thonon-les-Bains, LAlbaron, 1991; Jean-Noël Retière, Identités ouvrières. Histoire sociale d'un fief ouvrier en Bretagne. 1909-1990, Paris, L Harmattan, 1994.
} 
estabelecem que o "comunismo popular", ${ }^{29}$ na sua diversidade, carrega a marca dos grupos sociais que o engajaram localmente. $\mathrm{O}$ "centralismo democrático" e a ideologia marxista-leninista aparecem assim interpretados de maneira às vezes muito distante da ideia comum que se tem disso e são essas ideias que os dirigentes tentam impor. A utopia comunista é alvo de apropriações múltiplas ${ }^{30}$ e pode-se dizer que o comunismo somente conseguiu ser verdadeiramente bem sucedido onde ele encontrou formas de utopia popular e pré-constituída compatíveis com sua gramática simbólica. Ele não chegou a conquistar um quase monopólio da representação operária na França entre o fim dos anos 1930 e o fim dos anos 1970, impondo sua ideologia do exterior, mas cristalizando aparições utópicas anteriores e veiculadas inclusive pelo sindicalismo e pelas associações operárias e as camponesas. O sucesso da empresa da mobilização comunista ${ }^{31}$ deve, por consequência, ser apreendida tanto como o produto do trabalho de seus dirigentes internacionais e nacionais quanto como a resultante de múltiplos investimentos identitários de grupos às expectativas extremamente diversificadas que o discurso e a prática comunistas agregaram simbolicamente.

Apreender as raízes sociais e a atividade dos partidos políticos pelo estudo das redes

As pesquisas recentes conduzidas pela sociologia dos partidos políticos na França e na Grã-Bretanha, ${ }^{32}$ abriram oportunamente novas vias de investigação visando a não separar a análise das formas organizacionais, das práticas militantes ou ainda das estratégias políticas, daquela das propriedades sociais dos dirigentes e dos membros captados de maneira relacional e compreensiva.

\footnotetext{
${ }^{29}$ Para retomar a expressão de Serge Bonnet, ibid.

${ }^{30}$ Este ponto aparece igualmente quando se compara os diferentes partidos comunistas em nível nacional, assim como o faz, por exemplo, Marc Lazar para a França e a Itália. In: Maisons rouges. "Les partis communistes français et italiens de la Libération à nos jours", Paris, Aubier, 1992.

${ }^{31}$ Sobre esta noção e sua aplicação em ciência política, cf. Bernard Lacroix, "Ordre politique et ordre social. Objectivisme, objectivation et analyse du politique". In: Grawitz, M.; Leca, J. (dir.). Traité de science politique, Paris, Presses universitaires de France, vol. 1, p. 469-565, 1985.

${ }^{32}$ Ver o número 81 (vol. 21-2008) da revista Politix. Sciences sociales du politiques, consagrada à "Fábrica dos partidos na Grã-Bretanha", F. Sawicki et Ph. Vervaeke (Eds.).
} 
Estas pesquisas mostram que não se pode separar os partidos enquanto organizações, de seu entorno social, se se procura compreender como um dado partido chega a se enraizar em uma dada sociedade. $A u$ plus prés du terrain, localmente, é fácil constatar o quanto as fronteiras entre os partidos e seu entorno social são porosas. Existe assim um continuum de relações entre os dirigentes, os militantes, os adeptos, os simpatizantes e os eleitores. O partido se apoia em redes relacionais que se entrecruzam. Estas redes interpessoais são fundadas na partilha de valores ou interesses, elas são mantidas por interações nos diversos lugares de sociabilidade mais ou menos formais: associações, sindicatos, cooperativas, associações de ajuda mútua, cafés... Propus chamar de milieu partidário o conjunto destas relações sociais e recorrer à análise de redes para objetivar os contornos do meio partidário.

Insistir na importância das redes visa a lançar um olhar mais aguçado sobre as trajetórias dos militantes e dos dirigentes dos partidos englobando inclusive a diversidade seu recrutamento ao seio de um mesmo partido político segundo os lugares e as épocas. Isso permite discernir melhor as fronteiras do milieu partidário, concebido como o conjunto das relações consolidadas entre grupos cujos membros não têm necessariamente por finalidade principal participar da construção do partido político, ainda que de fato eles contribuam com isso pelas suas atividades. $\mathrm{O}$ foco lançado sobre as redes não constitui um fim em si mesmo. Ela serve para revelar, como escreve o antropólogo John A. Barnes, "entre outras coisas, as fronteiras e a estrutura interna dos grupos, ${ }^{33 "}$ neste caso, a estrutura de relações estáveis e historicamente constituídas entre setores sociais formalmente divididos (político, sindical, econômico, familiar, religioso...). De fato, burocracias não constituem a maioria nos partidos. Enquanto eles são dirigidos, na cúpula, por dirigentes profissionalizados que se reúnem regularmente, localmente, eles aparecem como organizações flexíveis e informais ou ainda como "nebulosas", como demonstrou, por exemplo, Mildred Schwartz a respeito do partido republicano no Illinois. ${ }^{34}$

${ }_{33}$ BARNES, J. A. "Networks and Political Process". In: MITCHELL, J. C. (Ed.). Social Networks. In: Urban Situations, Manchester University Press, p. 74, 1969.

${ }^{34}$ Mildred Schwartz tem entretanto uma concepção menos larga do meio partidário. Ela trata o partido como "uma rede de atores individuais e coletivos cujas atividades separadas e os engajamentos têm um objetivo partidário". SCHWARTZ, M. A. The Party Network: The Robust Organization of Illinois Republicans. Madison, University 
Este lado não é em nada uma fonte de fraqueza, mas manifesta pelo contrário a inscrição do laço partidário no fio das relações cotidianas.

Nas ciências sociais, o termo "rede" é utilizado para qualificar uma grande diversidade de canais de relações não apenas entre indivíduos; nos domínios da sociologia das ciências e das técnicas e das ciências da comunicação, ele serve inclusive para analisar as relações entre indivíduos, grupos, organizações e "objetos": ${ }^{35}$ fala-se então de redes "sociotécnicas". Do mesmo modo, a análise organizacional se interessa mais e mais pelas redes entre organizações, por exemplo, no âmbito das empresas, pelas relações entre fornecedores, subalternos e clientes considerados como "blocos". Estes diferentes usos da noção de rede e os riscos de confusão que decorrem disso implicam definir previamente o termo. Naquilo que me diz respeito, eu me limito a considerar apenas as redes interindividuais. No mais, se se quiser fazer da análise de redes um instrumento empírico rigoroso, é importante distinguir bem os diferentes tipos de rede interindividual que se podem encontrar quando se estuda um partido político. Quanto a mim, distingo ao menos cinco delas:

1. A rede como o conjunto das relações pessoais (pouco importa sobre o que estas relações estão fundadas: a amizade, a família, a vizinhança, a religião, a profissão, o clientelismo...), formais ou informais de um dado indivíduo (ego). De qualquer modo, trata-se aqui de determinar o capital social de um indivíduo singular, sua densidade, sua intensidade e sua extensão no espaço social. Em ciência política, esta acepção, como notou David Knoke, ${ }^{36}$ pode ser particularmente útil para analisar a influência política dos "notáveis" ou dos bosses das grandes cidades americanas. A característica da rede pessoal do notável ou do boss é precisamente ter relações nos meios sociais muito diferentes, mas também na administração e nos círculos de poder extralocais e

of Wisconsin Press, p. 257, 1990. Um membro eleito de um partido político que presta um serviço pessoal a um eleitor não o faz necessariamente com o objetivo de reforçar a dominação de seu partido, não restando dúvida que seu comportamento tenha toda chance de alcançar este efeito.

${ }^{35}$ Ver, por exemplo, a teoria do "ator-rede", proposta por Bruno Latour dans Re-assembling the Social: an introduction to actor-network Theory. Oxford, Oxford University Press, 2005.

${ }^{36}$ KNOKE, D. Political Networks. The Structural Perspective. Cambridge, Harvard University Press, p. 139sq, 1990. 
estar assim em posição de nó, isto é, em posição de agente (broker) ou de intermediário (gate-keeper), para ter acesso a numerosos recursos.

2. Mas a rede pode também remeter a uma realidade mais dominada pelos atores, ou seja, um sistema de afinidades duráveis fundado sobre interesses comuns, laços de dependência ou de obrigações, entre indivíduos que decidem se aliar entre eles no seio de uma organização ou de um dado setor da sociedade. Nos partidos políticos, este tipo de "aliança" caracteriza as cliques fracamente institucionalizadas por oposição às facções estatutárias ou manifestas. Estas cliques podem ser fundadas apenas sobre os interesses conjunturais, mas elas podem ter também um caráter mais durável e reunir os agentes oriundos de uma mesma região, de uma mesma geração ou de uma mesma profissão.

3. A rede pode designar também o sistema de relações estabilizadas entre indivíduos que ocupam posições, homólogas ou não, em setores de atividades distintas, mas implicadas em cooperar. O politólogo francês Michel Dobry ${ }^{37}$ chama esse tipo de rede de "rede de consolidação", na medida em que ele torna possíveis as "transações-colusões" entre setores sociais separados. Este conceito se aplica bem, segundo ele, ao funcionamento do Estado central, por exemplo, às relações entre poder político e setor militar, mas poder-se-ia aplicá-lo também às relações que os eleitos e os representantes de Estado mantêm entre si. Os sociólogos das empresas ligaram-se particularmente a este tipo de rede que remete às relações regulares estabelecidas entre atores pertencentes a organizações diferentes que não são reguladas por uma autoridade legítima ou por uma relação qualquer (compra de prestações, por exemplo). ${ }^{38}$

4. O conceito de rede, em uma acepção próxima da precedente, pode também remeter a um sistema estabilizado (até mesmo institucionalizado) de interdependência entre organizações que intervêm em diferentes setores, mas cujos atores são multiposicionados ${ }^{39}$ ou cujos mem-

${ }^{37}$ DOBRY, M. Sociologie des crises politiques. Paris, Presses de la FNSP, p. 110sq, 1986. (trad. espanhola: Sociologia de las crisis politicas, Madrid, 1988).

${ }^{38}$ Se elas podem ser fundadas sobre trocas informais, mas regulares, de informações, estas redes são, entretanto, muitas vezes consolidadas por contratos (joint ventures, alianças estratégicas, consórcios de pesquisa, acordos de outsourcing) e existem então de qualquer maneira fora dos indivíduos. Cf. PODOLNY, J. M.; PAGE, K. L. "Network Forms of Organization", Annual Review of Sociology, 24, p. 57-76, 1998.

${ }^{39}$ A multiposicionalidade remete aos indivíduos que intervêm em diferentes campos sociais e possuem dessa forma recursos suplementares que eles podem importar, sob 
bros dividem as mesmas crenças ou ideais. Os laços entre dirigentes e militantes dos partidos e dos grupos de interesse parecem assinalar tipicamente esta categoria. As relações regulares entre os atores destes diferentes mundos são constitutivos de redes que não são ligadas às pessoas, mas se inscrevem muitas vezes na longa duração, mesmo que na maior parte do tempo eles não estejam formalizados ou contratados, como existe no universo econômico.

5. Convém acrescentar a estes quatro tipos um quinto, que qualifica o conjunto das relações interpessoais entre os responsáveis das diferentes componentes de uma dada organização. O registro rigoroso deste conjunto de relações só pode ser feito em unidades restritas (uma pequena empresa, ${ }^{40}$ uma associação, por exemplo), mas nada impede de inferir, da frequência aproximadamente grande de relações entre alguns atores no seio de uma mesma organização mais vasta, os mecanismos de coordenação informal que permitem ao governo manter uma organização. É o que fez, por exemplo, Mildred Schwartz, ao estudar as relações entre as diferentes componentes do Partido Republicano no Illinois, inclusive entre as diferentes instituições públicas controladas por seus membros, ${ }^{41} \mathrm{~A}$ recorrência a esta concepção da rede aparece particularmente pertinente quando se trata de estudar as relações entre os diferentes lugares de poder que compõem um partido político: grupo parlamentar ou grupos políticos das coletividades locais, entornos ministeriais ou presidenciais, direção nacional ou local do partido...

Qualquer que seja o tipo de rede de que se trata, nenhuma se reduz a relações interpessoais sem laços com as posições e os papéis sociais ocupados pelos atores. Há sempre a tendência em opor sistematicamente as re-

\footnotetext{
algumas condições, de um campo a outro. Sobre essa noção, cf. BOLTANSKI, L. "Lespace positionnel. Multiplicité des positions institutionnelles et habitus de classe". Revue française de sociologie, (1), p. 3-26.

${ }^{40}$ Ver por exemplo a aplicação disso feita pelo sociólogo Emmanuel Lazega, a respeito dos escritórios de advogados: The Collegial Phenomenon. The Social Mechanisms of Cooperation among Peers in a Corporate Law Partnership, Oxford, Oxford University Press, 2001. A análise de rede global que ele propõe é, segundo ele, particularmente adaptada ao estudo das organizações colegiais, isto é, fracamente burocratizadas e hierarquizadas.

${ }^{41}$ Mildred Schwartz assinala a respeito do partido republicano que "o partido é organizado hierarquicamente, mas não em termos de relações de dominação, mas como um agregado de setores interdependentes". Schwartz, M. A. The Party Network, op. cit., p. 267.
} 
lações informais, isto é, fundadas sobre relações codificadas e frequentemente hierarquizadas, e as relações informais, em outras palavras, opõe-se a organização à rede. Na realidade, os atores estabelecem relações informais no decorrer de suas atividades no seio das organizações, ainda que eles pertençam à mesma organização ou a organizações diferentes. São as posições e os papéis que ocupam os indivíduos no mundo social que lhes abrem a possibilidade de se inserirem nas redes existentes e assim de modificarem eventualmente a forma delas. Não há, portanto, de um lado o mundo da ação organizada e do outro, o mundo das redes. Trata-se mesmo de duas faces da mesma realidade social: de um lado, os papéis e as posições aos quais se remetem certos recursos e deveres, do outro, o uso que alguns atores fazem disso. Como assinala o antropólogo social sueco Ulf Hannerz: "A noção de rede é certamente útil a partir do momento em que se interessa em indivíduos e no uso que eles fazem de seus papéis [no plural], mais do que em papéis e na maneira como estes revestem indivíduos; em práticas que estabelecem limites institucionais ou que os atravessam, mais do que em práticas que os confirmam." ${ }^{42}$

O secretário de seção de um partido político, se quiser preencher o melhor possível seu papel e consolidar sua posição, está obrigado a tecer relações com as pessoas que contam com seu território para o dinamismo do partido (leaders associativos, representantes eleitos, funcionários, jornalistas, formadores de opinião...); ele pode se apoiar sobre um capital social acumulado anteriormente na posição que ele ocupa (um secretário de seção, antigo sindicalista ou alto funcionário territorial, não tem os mesmos recursos de origem), mas frequentemente é esta posição que o incita e o põe em posição de tecer esses laços. Estes laços são na maior parte do tempo informais - exceto nos partidos que têm laços orgânicos com tal sindicato, associação ou entidade de ajuda mútua - mas eles só fazem sentido em relação à maneira como está estruturado o partido sobre um dado território. O responsável por um partido próximo dos meios religiosos deve entreter relações com os membros das autoridades e os militantes das associações caritativas ou de caráter social; fazendo isso, ele contribui com a perpetuação de um "sistema de ação" na acepção de

${ }^{42}$ HANNERZ, U. Explorer la ville. Éléments d'anthropologie urbaine. Paris, Minuit, p. 223, 1983, (1ère éd. Exploring the City, Columbia University Press, 1980). 
Michel Crozier e Ehrard Friedberg ${ }^{43}$ ou uma configuração, no sentido de Norbert Elias ${ }^{44}$ que eu chamo de "milieu partidário".

A análise em termos de redes é estrutural e não individualista: ele não deve dar a impressão que os atores são capazes de tecer as relações de maneira estratégica ou instrumental. Aplicada aos partidos, ela tem como principal mérito levar a olhar as atividades e as formas de organização partidárias como produtos particulares das relações concretas entre indivíduos e grupos que agem simultaneamente nos espaços sociais diferenciados. Ela obriga a considerar que as "estratégias" dos atores resultam de suas posições no meio partidário e dos interesses ou de recursos que são ligados a essas posições, assim como cálculos que eles são levados a fazer no contexto estrito da concorrência interna da organização. A abordagem pelas redes oferece um instrumento para dar conta das homologias entre funcionamento do partido ou de algumas de suas tendências e o de outras organizações (sindicatos, associações...). Ela permite não esquecer que a concorrência política (pelos postos de poder) se dá também em toda uma série de organizações que vão dos sindicatos a algumas associações passando pelas empresas públicas ou as administrações. Fundamentalmente, o conceito de rede chama a atenção para os mecanismos que explicam que os profissionais da política agem unicamente por sua própria conta, correndo o risco de perder os recursos que lhes confere o conjunto das redes com as quais eles estão envolvidos.

Os políticos, como os outros atores sociais, contrariamente ao modelo da rational choice, não são apenas homo œconomicus; eles não agem apenas por sua própria conta em virtude de um cálculo egoísta ditado pela única racionalidade da organização ou do mercado, pois, como assinala Jeremy Boissevin, "o indivíduo é dependente dos outros, é-lhe impossível realizar seu interesse pessoal sem levar em consideração os dos outros e sem que se possa demonstrar que sua ação vai lhes aproveitar, ou ao menos, não lhes prejudicar." ${ }^{45}$ Chamar a atenção para as redes que envolvem os atores políticos volta logo a integrar na análise a multiposicionalidade deles e a pluralidade dos modos de relações e de formas de interesse que

\footnotetext{
$\overline{{ }^{43} \text { CROZIER, M. }}$; FRIEDBERG, E. Lacteur et le système. Paris, Seuil, 1977.

${ }^{44}$ ELIAS, N. Qu'est-ce que la sociologie?, Aix-en-Provence, Pandora, 1981 (1ère éd. Was ist Soziologie? München, Juventa, 1970).

45 BOISSEVIN, J. Friends of Friends. Networks. Manipulators and Coalitions. Oxford, Basil Blackwell, p. 6, 1974.
} 
decorrem disso. Na prática, as relações de amizade ou de fidelidade, que podem ser fundadas sobre trocas múltiplas de serviços, ou a partilha de lembranças ligadas à participação em lutas comuns, e que são frequentemente dobradas por relações de parentesco que mantêm a estreiteza das redes militantes, não são menos importantes para compreender as interações políticas que sua dimensão conflituosa e concorrencial.

\section{A objetivação das redes partidárias: o exemplo do Partido Socialista Francês}

A objetivação das redes não é, entretanto, uma tarefa fácil. Se ela é relativamente simples quando se se interessa por um só indivíduo, pelo qual se faz um esforço em registrar o conjunto de relações sociais, ou por um pequeno grupo pelo qual se faz um esforço para recensear o conjunto das interações entre os membros, ela se torna muito difícil quando se tem necessidade de organizações vastas e ramificadas como o são os partidos políticos. Se este obstáculo ligado ao tamanho impede uma compatibilização rigorosa, ele não é anulador. Para identificar as redes nas quais se insere o Partido Socialista Francês, associei duas abordagens: uma análise do partido em alguns locais escolhidos de modo tipificado (influência mais ou menos forte do partido, antiguidade desigual de sua implantação, diversidade das características socioeconômicas e culturais dos territórios...) e um estudo detalhado da trajetória social e "militante" dos dirigentes, eleitos e militantes do partido a partir de questionários e de entrevistas biográficas aprofundadas. ${ }^{46}$ Escolher um terreno geograficamente limitado permite ao mesmo tempo estar atento às particularidades locais e apreender melhor a densidade de algumas redes sociopolíticas. Conduzir uma pesquisa intensa sobre os dirigentes, eleitos e militantes, considerados em seu contexto de ação quotidiano, permite por sua vez pôr em evidência as conexões que existem entre o partido e algumas organizações sindicais, patronais ou religiosas, mas também algumas famílias ou bairros. A pesquisa de campo permite compreender

\footnotetext{
${ }^{46}$ Resumo aqui brevemente o que foram o método e os principais resultados do meu estudo sobre o partido socialista nos departamentos do Pas-de-Calais (região industrial do norte da França), da Ille-et-Vilaine (região dominada pelo setor terciário público da Bretanha) e do Var (região ao mesmo tempo vinícola e turística do sul da França às margens do Mediterrâneo). SAWICKI, F. Les réseaux du parti socialiste. Sociologie d'un milieu partisan, Paris, Belin, 1997.
} 
melhor a natureza e a frequência dessas relações, na medida em que ela permite coletar informações sobre as políticas locais ou sobre as tomadas de posição do partido em favor de um ou outro desses grupos. A atenção dada às relações clientelistas certamente é parte integrante da pesquisa da análise: o exame de quem aproveita na verdade dos bens políticos personalizados é frequentemente um dos elementos mais reveladores das conivências entre o partido e tal ou tal grupo social. ${ }^{47}$

Comparando a sociologia dos principais dirigentes e eleitos de três federações do Partido Socialista francês nos anos 1980, eu pude assim pôr em evidência a existência de proximidades muito diferentes de acordo com diversos círculos e organizações. A imagem que resulta disso é antes de tudo a de um partido menos homogêneo do que se acredita. Em Pas-de-Calais, departamento marcado pela indústria e pela exploração carbonífera, o PS conservou uma forte ancoragem em meio operário graças aos laços com os militantes associativos e sindicais, à presença muito forte de eleitos que, ainda que tenham chegado muitas vezes à profissão docente, são majoritariamente de origem popular e $90 \%$ dentre eles nativos do território, e também à manutenção de um importante dispositivo de sociabilidade (festas, organização de bolões...) e ajuda mútua. A legitimidade do partido passa por um discurso de reivindicação territorial muito marcada que exige reparações dos prejuízos causados pela exploração de carvão. Em Ille-et-Vilaine, na Bretanha, o PS se desenvolveu no início dos anos 1970, apoiando-se em militantes oriundos dos sindicatos e das associações católicas, mas também sobre os militantes vindos dos meios anticlericais voltados para a defesa da escola pública em uma região fortemente católica. A combinação foi dificil, uma vez que esta clivagem continuou estruturando o partido até o início dos anos 1990. Mas os militantes de origem cristã importaram para o partido um espírito de tolerância e pragmatismo que acabou predominando, contribuindo para fazer do PS o herdeiro da democracia cristã. Em Var, finalmente, terceira região estudada, este velho departamento republicano e à esquerda da Côte d'Azur, pendeu no fim dos

\footnotetext{
47 Cesare Mattina pôs assim em evidência os laços privilegiados entre o partido socialista em Marseille e algumas minorias étnicas ou regionais (córsegos, armênios inclusive). Cf. "Changes in Clientelism and Urban Government: A Comparative Case Study of Naples and Marseille". International Journal of Urban and Regional Research, 31 (1), 2007 et "Mutations des ressources clientélaires et construction des notabilités politiques à Marseille (1970-1990)", Politix. Revue des sciences sociales du politique, n. 67, p. 129-155, october 2004.
} 
anos 1970 para a direita em razão da urbanização massiva que conheceu, haja vista o boom turístico e a afluência importante de aposentados que vão para lá descansar. Ancorado essencialmente no meio rural e nas pequenas cidades, o Partido Socialista não foi capaz de desenvolver suas redes nos novos centros urbanos. Fundado sobre os laços interpessoais de base fundamentalmente clientelista e familiar, a dominação do partido socialista foi progressivamente suprimida na medida em que este perdia os recursos públicos que controlou por muito tempo (as prefeituras, mas sobretudo, o Conselho geral, instância do governo do departamento, particularmente importante pelas propriedades rurais que não têm os recursos suficientes para fazer face a seus gastos apenas).

Se se divide a maioria dos pressupostos paradigmáticos da structural analysis tal como ela se desenvolveu nos Estados Unidos desde vinte $\operatorname{anos}^{48}$ aproximadamente e que resume bem a fórmula de "interacionismo estrutural", nossa abordagem repousa logo sobre um método mais indutivo, mais próximo daquela que os antropólogos sociais ingleses utilizaram, primeiros importadores deste conceito nas ciências sociais. ${ }^{49}$ Este uso mais flexível do conceito de rede autoriza uma melhor tomada de si da história e da mudança social negligenciada pelos defensores da análise estrutural. A existência de redes é, com efeito, a manifestação de relações historicamente consolidadas entre grupos ou organizações. As redes constitutivas de um milieu partidário não são, portanto, unicamente o resultado da ação voluntária dos atores políticos; seu desenvolvimento e sua ativação aparecem normatizadas por uma estrutura historicamente objetivada em instituições e regras. As relações familiares e a lembrança dos combates políticos passados e serviços prestados contribuem para inscrever as redes na longa duração. ${ }^{50}$ Mas se as organizações permanecem marcadas pelas condições originais que têm presidido sua institucionalização, mudanças de toda ordem afetam permanentemente a rede de redes constitutiva do meio partidário.

${ }^{48}$ Cf. Barry WELLMANN, B.; BERKOWITZ, S. D. (Eds.). Social Structures. A Network Approach. Cambridge, Cambridge University Press, 1988.

${ }^{49}$ É possível encontrar uma boa apresentação desta corrente, às vezes chamada de "Escola de Manchester", em MITCHELL, J. C. (Ed.). Social Networks..., op. cit. e BOISSEVIN, J.; Mitchell, J. C. (Eds.). Networks Analysis. La Haye, Mouton, 1973.

${ }^{50}$ Marc Abélès, Jours tranquilles en 89. Ethnologie politique d'un département français, Odile Jacob, 1989. La citation est tirée de ABÉLÈS, M. "Lanthropologue et le politique". In: Anthropologie: état des lieux. Paris, Le livre de poche, p. 223, 1986. 
Estar atento à evolução das redes pelas quais um partido se ancora em uma dada sociedade é precisamente estar em condições de identificar como mudanças que intervêm fora da política (por exemplo, no modo de recrutamento dos professores, na organização do sindicalismo por causa das mudanças econômicas, na Igreja por causa da marginalização das associações de ação católica...) afetam os partidos políticos, estancando suas redes tradicionais de influência. Inversamente, a entrada de novos membros no partido que dispõem de outras relações sociais (por exemplo, no mundo da empresa ou da alta administração, como foi o caso no interior do Partido Socialista Francês no fim dos anos 1970 e, sobretudo, depois de sua chegada ao poder em 1981) pode ajudar a compreender as mudanças nos equilíbrios internos do partido e a desqualificação de alguns dirigentes que não dispõem das mesmas conexões.

Certamente, a abordagem dos partidos políticos pelo estudo das redes não deve levar a perder de vista o trabalho específico realizado no nível de organização partidária stricto sensu para criar unidade, uma identidade comum, por exemplo, no meio da difusão de símbolos (cantos, emblemas, slogans...) ou da literatura partidária, de estágios de formação, de convocações à ordem, do controle dos meios de financiamento. Um partido, salvo caso limítrofe, não se resume, portanto, em apenas uma rede de redes. Ele é também uma instituição com suas próprias regras, escritas e não escritas, que se impõe a seus membros mais ativos. Seus dirigentes devem igualmente levar em conta as normas próprias do regime político e do sistema eleitoral nos quais estão inseridos. O modo de votar, as regras de financiamento dos partidos políticos, o caráter parlamentar ou presidencial do regime, a maior ou menor facilidade para reformar a constituição são outras "variáveis" que afetam grandemente as estratégias e também a organização dos partidos políticos. Muito frequentemente os teóricos dos partidos querem a todo custo impor sua definição como a única possível, esquecendo que um partido político é uma realidade social complexa, caleidoscópica, cuja afirmação depende primeiramente da problemática adotada, isto é, das questões feitas pelo pesquisador. Definir o partido como um milieu partidário e uma rede de redes consiste justamente em fornecer os meios para compreender como um partido se enraiza na sociedade, como esse enraizamento evolui segundo os lugares e as épocas; consiste também lançar luzes sobre algumas escolhas políticas feitas por este partido, e como elas são semelhantes, em outros contextos. 